\title{
Persistent benefits of rehabilitation on pain and life quality for nonambulatory patients with spinal epidural metastasis
}

\author{
Robert L. Ruff, MD, PhD; ${ }^{1-2 *}$ Suzanne S. Ruff, PhD; ${ }^{1}$ Xiaofeng Wang, $\mathbf{P h D}^{\mathbf{3}}$ \\ ${ }^{1}$ Neurology and Spinal Cord Injury and Dysfunction Services, Louis Stokes Cleveland Department of Veterans Affairs \\ Medical Center, Cleveland, $\mathrm{OH} ;{ }^{2}$ Department of Neurology, Case Western Reserve University, Cleveland, OH; \\ ${ }^{3}$ Department of Quantitative Health Sciences, The Cleveland Clinic, Cleveland, $\mathrm{OH}$
}

\begin{abstract}
We determined whether the benefits of directed rehabilitation for pain, depression, and satisfaction with life persisted for veterans who were nonambulatory after spinal epidural metastasis (SEM) treatment. Twelve consecutive veterans (paraplegic after SEM treatment) who received 2 weeks of directed rehabilitation were compared with a historical control group of thirty paraplegic veterans who did not receive rehabilitation. Subjects were followed until death. Pain levels, depression, satisfaction with life, and consumption of pain medication were measured. Subjects who received rehabilitation had less pain, consumed less pain medication, were less depressed, and had higher satisfaction with life. The benefits to the rehabilitated subjects persisted until their deaths. We conclude that spinal cord injury rehabilitation for nonambulatory subjects with SEM produces persistent benefits for pain, depression, and satisfaction with life.
\end{abstract}

Key words: cancer rehabilitation, depression, metastatic cancer, pain, pain medication, rehabilitation, satisfaction with life, spinal cord compression, spinal cord injury rehabilitation, spinal epidural metastasis.

\section{INTRODUCTION}

Many types of cancer metastasize to the spinal column, and 5 to 10 percent of people with cancer will develop a symptomatic spinal epidural metastasis (SEM) [1-4]. SEMs are present in the autopsies of one-third of cancer patients [5]. The annual incidence of SEM in the
United States increased from $\sim 18,000$ in 1987 to 25,000 in 1996 [4].

Pain control is an important issue for people with cancer, especially epidural cancer [6-11]. In studies of SEMs, pain was usually the initial manifestation of the spinal cancer and the most common symptom when the SEMs were recognized [3-4]. Less than 5 percent of people with SEM have no pain [1-4]. Prior studies demonstrated pain reduction following treatment with glucocorticoids and radiation therapy (RT) but did not report on pain for the remainder of the lives of the subjects with SEM [34,11-15].

We previously reported on the impact of rehabilitation for people who could not walk after completing SEM treatment [16]. Providing a 2-week directed rehabilitation training program related to skin care, transfers,

Abbreviations: ANOVA $=$ analysis of variance, ASIA = American Spinal Injury Association, BDI-II = Beck Depression Inventory-Second Edition, LSCVAMC = Louis Stokes Cleveland Department of Veterans Affairs Medical Center, NSAID = nonsteroidal anti-inflammatory drug, $\mathrm{RT}=$ radiation therapy, SCI = spinal cord injury, SEM = spinal epidural metastasis, SWLS = Satisfaction with Life Scale.

* Address all correspondence to Robert $\mathrm{L}$. Ruff, MD, PhD; Neurology Service 127(W), Louis Stokes Cleveland VAMC, 10701 East Boulevard, Cleveland, OH 44106; 215-791-3800, ext 5219; fax: 216-707-5934. Email: robert.ruff1@va.gov

DOI: 10.1682/JRRD.2007.01.0006 
incentive spirometry, and bladder and bowel management resulted in longer survival. Nonambulatory patients who received rehabilitation had a median survival of 26 weeks compared with 6 weeks for patients who did not receive rehabilitation. In addition, subjects who received rehabilitation had lower levels of pain, less depression, and higher satisfaction with life at the end of the rehabilitation program compared with a historical control group that was assayed at the comparable time of 2 weeks after completion of SEM treatment. However, the benefit of the rehabilitation program would be diminished if the improvements in pain, depression, and satisfaction with life did not persist. The rehabilitation program would be of dubious value if pain and depression returned and patients lived an extended period with discomfort and little satisfaction with life.

Here, we expand on the findings of our prior study of the impact of providing spinal cord rehabilitation to people who cannot walk after SEM treatment [16]. We report on the measures of pain, consumption of pain medication, depression, and satisfaction with life from the time of SEM treatment until death. The subjects who received directed rehabilitation maintained lower pain levels, consumed less pain medication, were less depressed, and had higher satisfaction with life for the remainder of their lives. In contrast, the subjects who did not receive rehabilitation remained depressed, maintained high pain levels despite increased pain medication use, and had declining satisfaction with life in the interval between completion of SEM treatment and death.

\section{METHODS}

Two groups of subjects were prospectively evaluated. The historical control group consisted of 30 subjects who were unable to walk after completing SEM treatment. These subjects did not receive spinal cord rehabilitation and are hereafter referred to as the "No Rehab" group. The second or intervention group contained 12 consecutive patients who were unable to walk after completion of SEM treatment. These subjects were offered and participated in a 2-week program of directed rehabilitation and are hereafter referred to as the "Rehab group." Patients were considered ambulatory if they could walk without human assistance at least 50 feet without stopping. Both patient groups were treated at the Louis Stokes Cleveland Department of Veterans Affairs Medi- cal Center (LSCVAMC). The No Rehab subjects were initially seen from March 1993 to December 1996. The Rehab subjects were evaluated from July 2001 to September 2004. We previously described additional details about the No Rehab [11] and Rehab groups [16]. SEM was diagnosed in all subjects by magnetic resonance imaging of the spine with a $1.5 \mathrm{~T}$ magnet-strength imaging machine. The SEM treatment for all subjects was RT combined with glucocorticoid medication (dexamethasone). Details of the SEM treatment were previously described [11]. All subjects reported here received the same RT protocol and dexamethasone dose.

The rehabilitation program emphasized training in transfers, bowel and bladder care, incentive spirometry, nutrition, and skin care. The 12 Rehab subjects began their programs within 1 day of completing SEM treatment. Consequently, the measurements made 2 weeks after completion of SEM treatment for the No Rehab group were temporally comparable with measurements made at the completion of rehabilitation for the Rehab group. We previously provided additional details about the rehabilitation program [16].

All patients had had detailed neurological physical examinations prior to SEM treatment, including classification of the severity and level of the myelopathy based on the American Spinal Injury Association (ASIA) classification system [17]. Briefly, the grades on the ASIA scale are as follows: $\mathrm{A}=$ complete myelopathy, $\mathrm{B}=$ sensory sparing without motor function, $\mathrm{C}=$ partial motor sparing with most tested muscles graded at $<3 / 5$ (not antigravity) on manual muscle testing, $\mathrm{D}=$ more complete motor sparing with most tested muscle graded at $>3 / 5$, and $E=$ no motor or sensory deficit. Patients were followed until their deaths. All patients were evaluated 2 weeks after completing SEM treatment, which corresponded to the end of the rehabilitation training program for the 12 Rehab subjects. After that point, all patients were followed by telephone contacts every 2 weeks, home visits every month, and outpatient visits every 3 months.

This study was approved and continuously reviewed by the Quality Assurance Committee of the Department of Neurology at Case Western Reserve University, the LSCVAMC Quality Assurance Service, the LSCVAMC Clinical Executive Committee, and the LSCVAMC Institutional Review Board. 


\section{Outcome Measures}

The outcome measures were self-reported pain levels, consumption of pain medication, depression, and satisfaction with life. We assayed outcome measures from the time of SEM diagnosis until death. We reported pain levels measured when SEM was diagnosed, before SEM treatment started, and after completion of SEM treatment. In addition, we recorded pain levels and consumption of pain medication 2 weeks after completion of SEM treatment and at all subsequent telephone contacts, home visits, and outpatient appointments, which occurred at least every 2 weeks. The final measures of pain and consumption of pain medications were obtained within 2 weeks of each subject's time of death. We assayed depression and satisfaction with life at the completion of SEM treatment, 2 weeks after completion of SEM treatment, and at each outpatient appointment and home visit. The last assays of depression and satisfaction with life were obtained within 1 month of each subject's death.

\section{Pain and Pain Medication Consumption}

Patients scored the highest pain level that they had experienced during the prior 24 hours on a numerical rating scale from 0 to 10 , with 0 being no pain and 10 unbearable pain [18]. Patients with pain levels of 4 or less were offered $650 \mathrm{mg}$ of acetaminophen four times a day for their pain. Patients with more intense pain were also offered nonsteroidal anti-inflammatory drugs (NSAIDs) and opioid medications. The amounts of acetaminophen, NSAIDs, and opioid medications required to treat pain were monitored for both patient groups. We used a standard equianalgesic pain medication conversion table [19] to compare the amount of pain medications (opioid alone and total of all pain medications) study subjects consumed each day.

\section{Depression and Satisfaction with Life}

Depression was assessed with the Beck Depression Inventory-Second Edition (BDI-II) [20]. Self-perceived satisfaction with life was assessed with the Satisfaction with Life Scale (SWLS) [21-22]. We previously reported the reliability and validity of the BDI-II and SWLS and their relevance to patients with spinal cord injury (SCI) and cancer [16].

\section{Statistical Methods}

We compared ASIA grades using the chi-square test or Fisher's exact test. Some secondary outcome measures showed nonnormality when the boxplot, histogram, and normal probability plot (normal Q-Q plot) of the data were checked [23]. Hence, we used the two-sample Wilcoxon Rank Sum Test [24], a nonparametric test also known as the "Mann-Whitney" test, to analyze all the outcome measures. The Wilcoxon Rank Sum Test requires that all the values in each sample follow the same continuous distribution and that, within each sample, the values are independent and identically distributed, which were reasonable assumptions in this study. We constructed random coefficient models to compare the two groups' temporal trends for each outcome variable [25-26]. The random coefficient models lead to covariance models that acknowledge variance in the outcome measures associated with longitudinal collection of data. We constructed analysis of variance (ANOVA) F-type tests [27] based on the random coefficient models to test for time trends in the outcome measures.

\section{RESULTS}

Values are shown as mean \pm standard error of the mean unless otherwise noted. As previously noted, the subjects in the two groups had similar ages, levels of education, types of cancers, and levels of spinal cord dysfunction [16]. The mean age for the Rehab group was $67.8 \pm 2.9$ years compared with $69.1 \pm 1.6$ years for the No Rehab group. The number of subjects in each ASIA grade after completing SEM treatment were as follows: Rehab $=6$ ASIA A and 6 ASIA B; No Rehab $=11$ ASIA A, 13 ASIA B, and 6 ASIA C.

\section{Pain}

At the onset of SEM treatment, patients indicated their highest pain levels within the past 24 hours using the 0 to 10 pain scale. The two groups had similarly high levels of pain before SEM treatment (Table 1). Pain levels for each group were lower after SEM treatment compared with before SEM treatment $(p<0.001)$. Both groups reported decreased pain, to a similar degree, in association with SEM treatment. Pain values did not vary according to the subjects' ASIA levels before or after SEM treatment.

Pain levels differed significantly 2 weeks after completion of SEM treatment (Table 1). Pain levels for the No Rehab group did not change during the 2 weeks after completion of SEM treatment. In contrast, after the 2-week 
Table 1.

Pain scores reported by subjects before, upon completion of, and 2 weeks after completion of spinal epidural metastasis (SEM) treatment, as well as last pain value before death. Pain rated on 0 (no pain) to 10 (unbearable pain) numerical rating scale.

\begin{tabular}{lcc}
\hline \multicolumn{1}{c}{ Time of Measure } & $\begin{array}{c}\text { Rehab } \\
(\boldsymbol{n}=\mathbf{1 2})\end{array}$ & $\begin{array}{c}\text { No Rehab } \\
(\boldsymbol{n}=\mathbf{3 0 )}\end{array}$ \\
\hline Pre-SEM Treatment & $8.9 \pm 0.3$ & $8.8 \pm 0.2$ \\
Post-SEM Treatment & $6.2 \pm 0.3$ & $6.4 \pm 0.3$ \\
2 Weeks Post-SEM Treatment ${ }^{\dagger}$ & $4.2 \pm 0.3$ & $6.4 \pm 0.3$ \\
Last Pain Level Before Death ${ }^{\dagger}$ & $3.0 \pm 0.2$ & $6.8 \pm 0.3$ \\
${ }^{*}$ Both groups’ pain levels were lower after vs before SEM treatment $(p<0.001)$. \\
${ }^{\dagger}$ Rehabilitation (Rehab) group had lower pain levels after completion of reha- \\
bilitation than after completion of SEM treatment ( $p<0.001)$ and lower pain \\
levels than No Rehabilitation (No Rehab) group ( $p<0.001)$. \\
${ }^{\ddagger}$ Rehab group had lower pain levels before death than No Rehab group $(p<$ \\
0.001) and lower pain levels than at 2 weeks after SEM treatment $(p<0.001)$. \\
\hline \hline
\end{tabular}

rehabilitation program, the Rehab group had lower pain levels than the No Rehab group and lower pain levels than prior to their entry into the rehabilitation program ( $p<0.001$ for both comparisons).

All patients were followed until death. Each subject's final pain level was recorded within 2 weeks of death. The Rehab group had lower final pain levels than the No Rehab group $(p<0.001)$ and lower pain levels than at the completion of the rehabilitation program $(p<0.001)$. The pain values for the No Rehab group did not improve after completion of SEM treatment (Table 1).

The lower pain levels reported by the Rehab group compared with the No Rehab group were not due to more aggressive medical treatment of pain for the Rehab subjects. To compare the amount of pain medications consumed by subjects, we converted total daily intake of acetaminophen, opioid medication, and NSAIDs to equivalent oral doses of morphine sulfate using standard pain medication conversion formulas (Table 2) [19]. At both 2 weeks after completion of SEM treatment and the last measure before death, subjects in the Rehab group consumed less opioid medication and less total pain medication (sum of acetaminophen, opioid medication, and NSAIDs) compared with subjects in the No Rehab group. At 2 weeks after completion of SEM treatment, subjects in the Rehab group consumed only 35 percent of the dose of opioid medications and 32 percent of the total pain medication dose compared with subjects in the No Rehab group.

Pain medication consumption for the Rehab subjects decreased in the interval between completion of SEM treatment and death. In contrast, pain medication consumption for the No Rehab subjects increased in the inter-
Table 2.

Subjects' pain medication use, converted to equianalgesic daily doses of orally ingested morphine. Use was converted for opioid medications and for total pain medications (acetaminophen, opioids, and nonsteroidal anti-inflammatory drugs).

\begin{tabular}{|c|c|c|}
\hline \multirow{2}{*}{ Time of Measure ${ }^{*}$} & \multicolumn{2}{|c|}{$\begin{array}{l}\text { Total Daily Dosing of } \\
\text { Pain Medication (mg) }\end{array}$} \\
\hline & $\begin{array}{l}\text { Rehab } \\
(n=12)\end{array}$ & $\begin{array}{c}\text { No Rehab } \\
(n=30)\end{array}$ \\
\hline \multicolumn{3}{|l|}{2 Weeks Post-SEM Treatment } \\
\hline Opioid & $44.5 \pm 1.2$ & $127 \pm 2.5$ \\
\hline Total Pain Medication & $52.5 \pm 1.3$ & $164 \pm 2.3$ \\
\hline \multicolumn{3}{|l|}{ Prior to Death } \\
\hline Opioid & $11.7 \pm 0.9$ & $246 \pm 3.3$ \\
\hline Total Pain Medication & $19.3 \pm 1.5$ & $352 \pm 3.8$ \\
\hline \multicolumn{3}{|c|}{$\begin{array}{l}\text { *At each measurement time, No Rehabilitation (No Rehab) group had higher } \\
\text { medication use ( } p<0.001 \text { both comparisons). Rehabilitation (Rehab) group's } \\
\text { medication use (opioid and total) decreased in period from } 2 \text { weeks after SEM } \\
\text { treatment to death ( } p<0.001 \text { both comparisons). In contrast, No Rehab } \\
\text { group's medication use (opioid and total) increased in period from } 2 \text { weeks } \\
\text { after SEM treatment to death ( } p<0.001 \text { both comparisons). }\end{array}$} \\
\hline
\end{tabular}

val between completion of SEM treatment and death. At death, subjects in the Rehab group consumed only 5 percent of the dose of opioid medications and 5 percent of the total pain medication dose compared with subjects in the No Rehab group (Table 2).

\section{Depression}

The Rehab and No Rehab groups had similar BDI-II scores at the completion of SEM treatment (Table 3). However, from 2 weeks after completion of SEM treatment until subject death, the Rehab subjects had lower BDI-II scores. The Rehab group's mean BDI-II score after the 2 week course of rehabilitation corresponded to minimal-to-mild depression. In contrast, the No Rehab group's mean BDI-II score indicated severe depression. At the last assessment before death, the Rehab group subjects had minimal depression, whereas the No Rehab group's BDI-II scores still corresponded to severe depression.

\section{Satisfaction with Life}

At the completion of SEM treatment, the two subject groups' SWLS scores were similar and indicated that the subjects were dissatisfied with life (Table 3). The SWLS scores for the No Rehab group did not improve after completing SEM treatment. The final SWLS scores for the No Rehab subjects were lower than their values after completion of SEM treatment ( $p<0.01$, Table 3). In contrast, the Rehab group had higher SWLS scores after 
Table 3.

Subjects’ Beck Depression Inventory-Second Edition (BDI-II) and Satisfaction with Life Scale (SWLS) scores after completion of spinal epidural metastasis (SEM) treatment and after completion of either 2 weeks directed rehabilitation (Rehab) or 2 weeks after completion of SEM treatment (No Rehab), as well as last values before death.

\begin{tabular}{|c|c|c|}
\hline Measure & $\begin{array}{l}\text { Rehab } \\
(n=12)\end{array}$ & $\begin{array}{c}\text { No Rehab } \\
(n=30)\end{array}$ \\
\hline \multicolumn{3}{|l|}{$\overline{\mathrm{BDI}}-\mathrm{II}$} \\
\hline Post-SEM Treatment & $30.3 \pm 2.4$ & $29.6 \pm 2.4$ \\
\hline $\begin{array}{l}2 \text { Weeks Post-SEM Treat- } \\
\text { ment }\end{array}$ & $13.2 \pm 3.5^{*}$ & $36.5 \pm 2.0$ \\
\hline Before Death & $12.2 \pm 3.2^{\dagger}$ & $39.6 \pm 2.2$ \\
\hline \multicolumn{3}{|l|}{ SWLS } \\
\hline Post-SEM Treatment & $11.2 \pm 0.8$ & $10.8 \pm 0.6$ \\
\hline $\begin{array}{l}2 \text { Weeks Post-SEM Treat- } \\
\text { ment }\end{array}$ & $27.0 \pm 0.7^{*}$ & $11.1 \pm 0.7$ \\
\hline Before Death & $28.4 \pm 0.9^{\dagger}$ & $7.6 \pm 0.6^{\ddagger}$ \\
\hline \multicolumn{3}{|c|}{$\begin{array}{l}\text { *After rehabilitation, Rehab group had lower BDI-II and higher SWLS scores } \\
\text { compared with their scores before rehabilitation and with No Rehab group }(p< \\
0.001 \text { all comparisons). } \\
{ }^{\dagger} \text { Before death, Rehab group maintained lower BDI-II and higher SWLS scores } \\
\text { compared with No Rehab group }(p<0.001) \text {. } \\
{ }^{\ddagger} \text { No Rehab group’s SWLS scores were lower before death compared with } \\
2 \text { weeks after SEM treatment }(p<0.01) \text {. }\end{array}$} \\
\hline
\end{tabular}

completion of rehabilitation compared with the start of rehabilitation $(p<0.001)$. At completion of the rehabilitation program and thereafter, the Rehab group had higher SWLS scores compared with the No Rehab group (Table 3). After completion of the rehabilitation program, the Rehab group's SWLS scores indicated satisfaction with life.

\section{Time Trends for Outcome Measures}

Our primary study question was whether subjects who received rehabilitation had reduced pain, consumption of pain medication, and depression and increased satisfaction with life that persisted for the remainder of their lives. Since we collected the data longitudinally, we considered regression models for each outcome measure during the intervals from initial evaluation until death. We then tested whether the time trend for each outcome measure was statistically different between the two groups. Three primary sources of random variation for our longitudinal data were (1) variation among subjects, (2) variation within subjects, and (3) variation caused by the process of measuring a particular subject at a particular time. These variation sources played an important role in determining the nature of the covariance matrix of the data. Analyzing the data with a conventional linear regression model that assumed independent identical distributed random errors for the data would not have been appropriate. The random coefficient models led to covariance models that accommodated the potential variations just discussed [25-26]. The resulting statistical models allowed us to test for differences in the time trends of the outcome measures using ANOVA F-type tests [27]. As shown in Table 4, the time trends significantly differed between the groups for each outcome measure. The data in Table 4 statistically supports the assertion that subjects who received rehabilitation had reduced pain, consumption of pain medication, and depression and increased satisfaction with life that persisted for the remainder of their lives.

\section{DISCUSSION}

Our findings suggest that the 2-week program of directed rehabilitation was associated with reduced pain and depression and improved satisfaction with life that persisted for the remainder of the subjects' lives. We believe that the differences in outcomes resulted from the 2-week rehabilitation program. However, other factors could have contributed to the differences in the two groups' outcomes. The Rehab and No Rehab groups were evaluated at different times. The software for the magnetic resonance imager used to diagnose SEM was upgraded several times during the interval between enrollment of the first subject in the No Rehab group and the last subject in the Rehab group. However, we do not believe that upgrades in the imaging software appreciably affected the outcomes of the two study groups.

Table 4.

Tests of time trends for two groups (rehabilitation vs no rehabilitation) based on random coefficient models. Analysis of variance $F$-type tests were used. All time trends significantly differed between groups for each outcome measure $(p<0.001)$.

\begin{tabular}{lcccc}
\hline Analysis Variable & BDI-II & Pain Level & SWLS & \multicolumn{2}{c}{ Pain Medication Consumption } \\
\cline { 4 - 5 } & & & & Opioids Only \\
\hline F-Statistic & 150.9 & 194.7 & 77.1 & 727.5 \\
\hline
\end{tabular}


Table 4.

Tests of time trends for two groups (rehabilitation vs no rehabilitation) based on random coefficient models. Analysis of variance F-type tests were used. All time trends significantly differed between groups for each outcome measure $(p<0.001)$.

BDI-II = Beck Depression Inventory-Second Edition, SWLS = Satisfaction with Life Scale.

Improvements in imaging techniques could have enhanced recognition of SEM for patients with minor lesions. However, the subjects in this study all had severe, easily visualized spinal canal lesions [11]. We are unaware of any changes in the SEM treatment protocol during the period when the No Rehab subjects were treated compared with the period when the Rehab subjects were treated. The definition of the RT ports and RT dosing did not change after 1991, when we increased the margins of the RT ports to reduce the likelihood of local reoccurrence of SEM [28]. Alterations in the SEM treatment protocol could have altered the likelihood of improvements in SEM-induced myelopathy during SEM treatment. However, the two study groups included patients who did not improve during SEM treatment. Despite our argument that the two subject groups had similar SEM treatment, unrecognized differences in the experiences of the two groups could possibly have contributed to the differences in outcomes.

The two groups had different dispositions [16]. Most (75\%) of the subjects in the Rehab group were discharged home, whereas only 20 percent of the No Rehab group returned home. The subjects who did not return home were transferred to the LSCVAMC long-term care unit. We believe that a larger fraction of the Rehab subjects returned home because the rehabilitation program prepared them and their caregivers to accomplish activities of daily living at home. We are unaware of changes in discharge disposition policy at the LSCVAMC during the study period that would have increased the Rehab group's likelihood of disposition to home. However, unrecognized changes in care delivery may have contributed to more of the Rehab group being discharged home.

Another group difference that likely contributed to the differences in pain, depression, and satisfaction with life was that the Rehab subjects were more likely to be able to transfer independently [16]. None of the No Rehab subjects were able to independently transfer, whereas 67 percent of the Rehab subjects were able to independently transfer from bed to wheelchair. In addition, the subjects and caregivers in the Rehab group were taught to manage bowel and bladder function. We believe that the Rehab group's increased likelihood of returning home, independently transferring, and having bowel and bladder management programs contributed to their higher satisfaction with life and may have elevated mood and reduced perceived intensity of pain.

Several factors likely contributed to the pain experienced by the subjects [7,29-33]. Pain associated with SCI can result from damage to pain transmission and modulation pathways [32-43]. In addition, pain may be due to cancer metastasis to bone and other processes involved in cancer pain [6-7,9,44].

Rehabilitation training included training in transfers and skin care. The increased mobility that these subjects gained from training in transfers and skin ulcer prevention may have contributed to lower pain levels. The continued reduction in pain levels after completion of SEM treatment for the subjects who received rehabilitation compared with the subjects who did not receive rehabilitation may be partly due to prevention of pain from skin ulcers or inactivity-related joint pathology [40-41].

Pain was addressed in the study subjects with acetaminophen, opioid medication, and NSAIDs. Recent studies indicate that specific anticonvulsant medications may help reduce pain associated with SCI [35,37]. These anticonvulsants may impact pain by interacting with gamma-aminobutyric acid receptors, by inhibiting the actions of excitatory amino acid neurotransmitters, or by both mechanisms $[29,33,35-37,43,45]$. The subjects in this study were not treated with anticonvulsant medication for pain because anticonvulsant medications had not yet been proven useful for treating SCI-associated pain. Consequently, treatment with anticonvulsant medications did not contribute to differences in pain levels between the study groups.

Table 2 indicates that the improved pain levels for the Rehab subjects were not due to increased consumption of pain medications. Rather, higher pain levels were associated with higher consumption of pain medication. While opioid medications are used to reduce pain, they may alter sleep patterns and thus have adverse effects on perceived levels of pain [40].

As previously discussed, a weakness of this study was the temporal separation of the two groups' evaluation periods. A more convincing protocol for evaluating 
the impact of rehabilitation for people unable to walk after SEM treatment would be a randomized multicentered clinical trial. Hopefully, the findings presented here and previously [16] will stimulate and justify a randomized clinical trial.

\section{CONCLUSIONS}

This study suggests that rehabilitation designed to help patients and their caregivers accommodate to the challenges produced by SCI should be offered to people who have severe myelopathy after RT treatment for SEM. Patients who received rehabilitation not only lived longer but also had better quality of life for the remainder of their lives. The value of rehabilitation is solidified by the finding that the benefits of rehabilitation on pain, depression, and self-perceived quality of life persisted for the remainder of the subjects' lives.

\section{ACKNOWLEDGMENTS}

This material was based on work supported by a grant from the Department of Veterans Affairs, Office of Research and Development, Rehabilitation Research and Development Service.

The authors have declared that no competing interests exist.

\section{REFERENCES}

1. Barron KD, Hirano A, Araski S, Terry RD. Experiences with metastatic neoplasms involving the spinal cord. Neurology. 1959;9(2):91-106. [PMID: 13622902]

2. Gilbert RW, Kim JH, Posner JB. Epidural spinal cord compression from metastatic tumor: Diagnosis and treatment. Ann Neurol. 1978;3(1):40-51. [PMID: 655653]

3. Posner JB. Neurologic complications of cancer. Philadelphia (PA): F. A. Davis; 1995. p. 482.

4. Lada R, Kaminski HJ, Ruff RL. Metastatic spinal cord compression. In: Vecht C, editor. Neuro-oncology Part III. Neurological disorders in systemic cancer. Amsterdam (the Netherlands): Elsevier Biomedical Publishers; 1997. p. 167-89.

5. Bach F, Larsen BH, Rohde K, Borgesen SE, Gjerris F, Boge-Rasmussen T, Agerlin N, Rasmusson B, Stjernholm P, Sorensen PS. Metastatic spinal cord compression. Occurrence, symptoms, clinical presentations and progno- sis in 398 patients with spinal cord compression. Acta Neurochir (Wien). 1990;107(1-2):37-43. [PMID: 2096606]

6. Portenoy RK, Lipton RB, Foley KM. Back pain in the cancer patient: An algorithm for evaluation and management. Neurology. 1987;37(1):134-38. [PMID: 2948135]

7. Foley KM. The treatment of cancer pain. N Engl J Med. 1985;313(2):84-95. [PMID: 2582259]

8. Galasko CS, Sylvester BS. Back pain in patients treated for malignant tumours. Clin Oncol. 1978;4(3):273-83.

[PMID: 86402]

9. Posner JB. Back pain and epidural spinal cord compression. Med Clin North Am. 1987;71(2):185-205. [PMID: 2950289]

10. Ruff RL, Lanska DJ. Epidural metastases in prospectively evaluated veterans with cancer and back pain. Cancer. 1989;63(11):2234-41. [PMID: 2524249] Erratum in: Cancer. 1990;66(5):935.

11. Zaidat OO, Ruff RL. Treatment of spinal epidural metastasis improves patient survival and functional state. Neurology. 2002;58(9):1360-66. [PMID: 12011281]

12. Maranzano E, Latini P. Effectiveness of radiation therapy without surgery in metastatic spinal cord compression: Final results from a prospective trial. Int J Radiat Oncol Biol Phys. 1995;32(4):959-67. [PMID: 7607970]

13. Zelefsky MJ, Scher HI, Krol G, Portenoy RK, Leibel SA, Fuks ZY. Spinal epidural tumor in patients with prostate cancer. Clinical and radiographic predictors of response to radiation therapy. Cancer. 1992;70(9):2319-25.

[PMID: 1394060]

14. Greenberg HS, Kim JH, Posner JB. Epidural spinal cord compression from metastatic tumor: Results with a new treatment protocol. Ann Neurol. 1980;8(4):361-66.

[PMID: 7436380]

15. Vecht CJ, Haaxma-Reiche H, Van Putten WL, De Visser M, Vries EP, Twijnstra A. Initial bolus of conventional versus high-dose dexamethasone in metastatic spinal cord compression. Neurology. 1989;39(9):1255-57. [PMID: 2771077]

16. Ruff RL, Adamson VW, Ruff SS, Wang X. Directed rehabilitation reduces pain and depression while increasing independence and satisfaction with life for patients with paraplegia due to epidural metastatic spinal cord compression. J Rehabil Res Devel. 2007;44(1):1-10.

17. Kirshblum S, Donovan WH. Neurological assessment and classification of traumatic spinal cord injury. In: Kirshblum S, Campagnolo DL, DeLisa JA, editors. Spinal cord medicine. Philadelphia (PA): Lippincott Williams \& Wilkins; 2002. p. 82-95.

18. Kremer E, Atkinson JH, Ignelzi RJ. Measurement of pain: Patient's preference does not confound pain measurement. Pain. 1981;10(2):241-48. [PMID: 7267140]

19. Gammaitoni AR, Fine P, Alvarez N, McPherson ML, Bergmark S. Clinical application of opioid equianalgesic data. Clin J Pain. 2003;19(5):286-97. [PMID: 12966254$]$ 
20. Beck AT, Steer RA, Brown GK. Beck Depression Inventory. 2nd ed. San Antonio (TX): The Psychological Corporation; 1996. p. 128.

21. Diener E, Emmons RA, Larsen RJ, Griffin S. The Satisfaction with Life Scale. J Pers Assess. 1985;49(1):71-75. [PMID: 16367493]

22. Pavot W, Diener E. Review of the Satisfaction with Life Scale. Psychol Assess. 1993;5(2):164-72.

23. Miller RG. Beyond ANOVA: Basics of applied statistics. Boca Raton (FL): Chapman \& Hill; 1997.

24. Hollander M, Wolfe DA. Nonparametric statistical methods. 2nd ed. New York (NY): John Wiley \& Sons; 1999. p. 68-75.

25. Diggle P, Liang KY, Zeger SL. Analysis of longitudinal data. New York (NY): Oxford University Press; 2002. p. 168.

26. Davis CS. Statistical methods for the analysis of repeated measurements. New York (NY): Springer; 2002. p. 322.

27. Verbeke G, Molenberghs G. Linear mixed models for longitudinal data. New York (NY): Springer; 2000. p. 269.

28. Kaminski HJ, Diwan VG, Ruff RL. Second occurrence of spinal epidural metastases. Neurology. 1991;41(5):744-46. [PMID: 2027494]

29. Siddall PJ, Loeser JD. Pain following spinal cord injury. Spinal Cord. 2001;39(2):63-73. [PMID: 11402361]

30. Burchiel KJ, Hsu FP. Pain and spasticity after spinal cord injury: Mechanisms and treatment. Spine. 2001;26(24 Suppl): S146-60. [PMID: 11805622]

31. Yezierski RP. Pain following spinal cord injury: The clinical problem and experimental studies. Pain. 1996;68(2-3): 185-94. [PMID: 9121805]

32. Finnerup NB, Jensen TS. Spinal cord injury painMechanisms and treatment. Eur J Neurol. 2004;11(2):73-82. [PMID: 14748766]

33. Rowbotham MC. Mechanisms of neuropathic pain and their implications for the design of clinical trials. Neurology. 2005;65(12 Suppl 4):S66-73. [PMID: 16385106$]$

34. Pagni CA. Central pain due to spinal cord and brain stem damage. In: Wall PD, Melzack R, editors. Textbook of pain. 2nd ed. Edinburgh (Scotland): Churchill Livingstone; 1989. p. 634-55.
35. Siddall PJ, Cousins MJ, Otte A, Griesing T, Chambers R, Murphy TK. Pregabalin in central neuropathic pain associated with spinal cord injury: A placebo-controlled trial. Neurology. 2006;67(10):1792-1800. [PMID: 17130411$]$

36. Eaton MJ. Cell and molecular approaches to the attenuation of pain after spinal cord injury. J Neurotrauma. 2006;23(3-4): 549-59. [PMID: 16629636]

37. Coderre TJ, Kumar N, Lefebvre CD, Yu JS. Evidence that gabapentin reduces neuropathic pain by inhibiting the spinal release of glutamate. J Neurochem. 2005;94(4):1131-39. [PMID: 16092950]

38. Finnerup NB, Gyldensted C, Nielsen E, Kristensen AD, Bach FW, Jensen TS. MRI in chronic spinal cord injury patients with and without central pain. Neurology. 2003; 61(11):1569-75. [PMID: 14663044]

39. Finnerup NB, Johannesen IL, Bach FW, Jensen TS. Sensory function above lesion level in spinal cord injury patients with and without pain. Somatosens Mot Res. 2003; 20(1):71-76. [PMID: 12745445]

40. Widerstrom-Noga E. Chronic pain and nonpainful sensations after spinal cord injury: Is there a relation? Clin J Pain. 2003;19(1):39-47. [PMID: 12514455]

41. Widerstrom-Noga EG, Felipe-Cuervo E, Yezierski RP. Relationships among clinical characteristics of chronic pain after spinal cord injury. Arch Phys Med Rehabil. 2001;82(9): 1191-97. [PMID: 11552190]

42. Nurmikko TJ. Mechanisms of central pain. Clin J Pain. 2000;16(2 Suppl):S21-25. [PMID: 10870736]

43. Eide PK. Pathophysiological mechanisms of central neuropathic pain after spinal cord injury. Spinal Cord. 1998;36(9): 601-12. [PMID: 9773443]

44. Campa JA 3rd, Payne R. The management of intractable bone pain: A clinician's perspective. Semin Nucl Med. 1992; 22(1):3-10. [PMID: 1589804]

45. Eaton MJ, Martinez M, Karmally S, Lopez T, Sagen J. Initial characterization of the transplant of immortalized chromaffin cells for the attenuation of chronic neuropathic pain. Cell Transplant. 2000;9(5):637-56. [PMID: 11144961]

Submitted for publication January 12, 2007. Accepted in revised form April 2, 2007. 